\title{
LA TRAGEDIA GRIEGA CONSIDERADA COMO UN OFICIO TRADICIONAL*
}

A typical representation, a regularity and an assertion of general outlines are common elements in Homer's poetical devices. They reflect the success of certain forms which are useful to the poet, having been learnt by him and then repeated as techniques of the craft. All of this has bearing when applied to Greek tragedy within its historical circunstances and also taking into account the knowledge we have on how culture was transmitted in the Athens of the $5^{\text {th century. The }}$ situation in Athens, as far as general literary tradition is concerned, is similar in some ways to what is known about the learning of oral techniques of composition. Rhetoric is also a witness on the importance of the method of learning based upon memory; in fact rhetoric did nothing more than become aware of a series of resources which were common in its class, though not so in its particular varieties, to the different literary genres cultivated in Greece at the time. The problem we are faced with is to decide whether a specific training existed or not, to give would-be tragedians the means traditionally used in tragedy, or whether the normal literary education could have sufficed for a young Athenian to begin his experiments in tragedy. In fact the texts of the tragic authors show, apart from those resources common to all poetic literature of the period, special means which imply that a special training was necessary.

I. En cierto sentido la idea que da el título a este trabajo es un lugar común, propio de cualquier manual elemental de Historia de la Literatura Griega y una afirmación obvia para cualquier lector de tragedias atenienses. No es mi intención, sin embargo, perder mi tiempo y el de mis posibles lectores glosando un lugar común, sino intentar comprenderlo un poco mejor observando de cerca algunas de sus implicaciones concretas. Para ello insistiré más que en el concepto de tradición en el de oficio.

* Versión ampliada de una lección tenida en las universidades de Liverpool (3-3-1977) y Southampton (7-3-1977). Quiero expresar aqui mi cordial agradecimiento a los profesores Giuseppe Giangrande y Francis Cairns y al Dr. Frederick Williams, y a cuantas personas me acogieron con tan hospitalaria amabilidad, en especial los profesores A. A. Long (Liverpool) y H. D. Rankin (Southampton). 
E1 concepto de tradición es, en efecto, excesivamente general y ambiguo para ser útil. En cierto modo toda forma literaria es tradicional en mayor o menor grado; hoy día se escriben novelas en una tradición que arranca de Joyce, en el siglo xix existió una tradición de novela realista burguesa, pero nadie estará dispuesto a admitir que podemos llamar tradicionales a esos dos fenómenos en el mismo sentido en que podemos considerar tradicional la tragedia griega.

Como toda noción excesivamente general el concepto de tradición necesita ser despiezado y reducido a diversos elementos; necesitamos operar con piezas más simples y más concretas, cuya atribución o no a la tragedia griega sea, por concretas, significativa.

Además necesitamos prescindir de ciertas envolturas accesorias que acompañan a la tragedia, que la condicionan indudablemente, pero que no son la tragedia. Me refiero a todo lo que podemos llamar convenciones externas, un juego de reglas explícitas que el poeta conocía de antemano y de las que era plenamente consciente, pero que una vez reconocidas no tienen mucha importancia. Tal es el número de actores y de coreutas, el marco institucional de los festivales dramáticos, la necesidad de presentar un número determinado de piezas, toda la serie de condicionantes institucionales, reales pero ajenos a la tragedia en si tal como vive hoy en nuestros textos, o mejor aún tal como podría vivir si contásemos con partituras musicales y con una perfecta comprensión del metro.

2. Tradición pues exclusivamente literaria, verbal si se quiere, que debemos comprender en manisfestaciones parciales y concretas. ¿Pero dónde encontraremos los útiles teóricos que nos permitan ese análisis de la tradición? ¿Al margen de la propia tragedia griega hay alguna tradición literaria que nos proporcione los criterios que necesitamos? Naturalmente lo prudente será buscar lo más cerca posible de la propia tragedia, tanto en el espacio como en el tiempo.

Hay en efecto un género que podemos llamar tradicional por antonomasia, género griego como la tragedia y que ha influido en ella profundamente. Me refiero, como es fácilmente adivinable, a la poesía homérica. Ciertamente cada nuevo progreso realizado en el estudio de los poemas homéricos desde los trabajos reveladores de Milman Parry no ha hecho sino poner más de manifiesto el entramado tradicional sobre el que están compuestos. La razón es obvia; la composición oral no es sino una forma particular de tradicionalidad, una forma, diríamos, extremosa. La tradición condiciona a través de las fórmulas la expresión misma del poeta, aspecto este el más llamativo y más comentado, pero no el único; a la vez la tradición condiciona la combinación de 
LA TRAGEDIA GRIEGA CONSIDERADA COMO UN OFICIO TRADICIONAL 175

ideas o de datos con que se construye un razonamiento o una descripción, la sucesión de incidentes que constituyen el esquema básico de un relato. Son éstos, aspectos en los que sólo recientemente se ha insistido al estudiar los poemas homéricos como poesía oral, pero que no tienen menor importancia que las consabidas fórmulas en la definición del género ${ }^{1}$. Tenemos pues un género tradicional que desde hace años se viene estudiando como tal y que, salvadas las indiscutibles diferencias que le separan de cualquier género no oral, puede tal vez proporcionarnos ciertos criterios, ciertos instrumentos de análisis, aplicables a la tragedia. Veamos escuetamente cuáles son esos criterios.

La poesía homérica tiene una forma específica como resultado de unas circunstancias digamos técnicas. Es obra de profesionales que conocen un oficio, oficio tradicional sin duda -todos lo son excepto en el momento de su nacimiento - que los poetas han aprendido con indudable trabajo a lo largo de un perfodo amplio de tiempo. Todo esto se deduce inapelablemente de las caracteristicas internas de la poesía homérica y de la comparación con otras literaturas orales sobre las que tenemos más amplia información. Hemos llegado así a poner el énfasis, como ya anuncié al principio, en el concepto de oficio antes que en el de tradición, oficio bien entendido no necesariamente en cuanto medio de vida - Hesíodo no vivía de componer hexámetros-, sino en cuanto técnica que exige aprendizaje ${ }^{2}$.

La poesía homérica opera sobre una materia bruta que le viene dada de antemano tanto en lo que se refiere a la expresión, una lengua especial distinta de la hablada por el poeta, como en lo que se refiere al contenido, un conjunto de viejas historias mil veces repetidas en que intervienen personajes de rasgos fijados por la tradición. Fste es un aspecto banal del problema y por lo demás trasladable directamente a la tragedia sobre todo si tenemos en cuenta la lengua de las partes corales.

Más importancia tienen las manifestaciones del oficio tradicional

1 Algunas investigaciones en esos campos además de las citadas en las nn. 2 de p. 176 y $2-5$ de 177 J. H. Gaisser, "A Structural Analysis of the Digressions in the Iliad and the Odyssey», HSCP 73, 1969, pp. 1-43; D. Lohman, Die Komposition der Reden in der Ilias, Berlin, 1970; W. W. Minton, "Invocation and Catalogue in Hesiod and Homerw, TAPhA 93, 1962, pp. 188-21 2; W. Nicolai, Kleine und grosse Darstellungseinheiten in der Ilias, Heidelberg, 1973.

- La posición social de Hesiodo en virtud de su poesía parece semejante a la de los expertos, aunque no especialistas, que actúan ocasionalmente y que están atestiguados en diversas culturas: R. Finnegan, Oral Poetry, Cambridge, I977, p. I95 y ss. 
cuando afectan a la vez a la expresión y al contenido, es decir a los aspectos propiamente literarios. Aquí podemos distinguir grosso modo varios niveles organizados jerárquicamente en una línea de complejidad que va desde el grupo de palabras hasta el poema completo.

En primer lugar tenemos la fórmula en sus diversas manifestaciones que todavía hoy no logramos comprender plenamente. En todo caso no es probable que la fórmula pueda ser de gran interés a la hora de analizar la tragedia; si todos los elementos de la tradición implican repeticiones sólo la fórmula supone repeticiones literales y esa peculiaridad es un producto de las necesidades especiales de un poeta oral que debe improvisar. No era ésta la situación del poeta trágico, como bien sabemos ${ }^{1}$.

Más allá de la fórmula nos encontramos en un territorio complejo y todavía no bien estudiado. Huiremos de los problemas y procuremos limitarnos a datos muy seguros. No serán todos los que la poesía homérica puede ofrecernos, pero al menos intentaremos no incurrir en el confusionismo que en este punto caracteriza a algunos oralistas.

En primer lugar encontramos "motivos», es decir, contenidos mínimos reconocibles y repetidos, el padre anciano que llora a su hijo único muerto en combate, los caballos que arrastran un carro vacío añorando a su dueño, por limitar nuestros ejemplos a lo que pudiéramos llamar patetismo de la guerra ${ }^{2}$. Lo que define a los motivos son las referencias concretas al mundo ficticio de los poemas, es su significado al margen de la forma en que se expresan. No necesitamos citar el texto griego para hacernos una idea clara de ellos; tampoco podemos reducirlos a esquemas abstractos de relaciones formales.

Similar a los motivos pero algo más complejo es lo que llamaremos patrón, una estructura abstracta en que intervienen dos o más motivos cuyas relaciones mutuas responden a un esquema definible desde un punto de vista lógico, y por supuesto repetido en los poemas. Es el caso de las reflexiones generales en algunas de sus formas más típicas, por ejemplo la que ha sido denominada "aplicación descriptiva": en un pasaje célebre del comienzo de la Odisea Zeus proclama que los

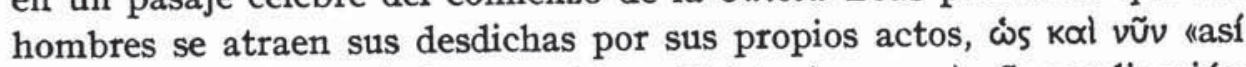
ahora" eso es lo que le ha ocurrido a Egisto ( $\alpha 32$ ss.). Generalización e ilustración narrativa, en ese orden y supeditada la primera a la se-

1 Pero tampoco debemos confundir las circunstancias en que componia su obra con las del autor moderno; cf. p. 187, n. 2.

- G. S. Kirk, The Songs of Homer, Cambridge, 1962, pp. 341-4. 
gunda, constituyen un esquema abstracto válido para multitud de pasajes en la literatura griega, de ellos varios homéricos ${ }^{1}$.

Un paso adelante nos lleva a la combinación de patrones o de grupos de motivos. A veces se tratará de una forma de composición poco compleja pero amplia, el catálogo, por ejemplo, con cada uno de sus uitems" organizado de acuerdo con el mismo patrón riguroso ${ }^{2}$; en otros casos un conjunto de motivos se nos aparecerá como una unidad que intuitivamente describimos con términos vulgares como incidente o escena, es el caso del "reproche»: se nos describe el combate de griegos y troyanos, un héroe troyano reprocha a otro -normalmente a Héctor o Eneas- su falta de agresividad, el héroe censurado reacciona, el combate continúa ${ }^{8}$. En cada uno de los momentos de un incidente como ese pueden figurar varios motivos; el incidente es una unidad de composición superior que los engloba.

Con frecuencia a situaciones o complejos formales de ese tipo se les denomina temas ${ }^{4}$. Personalmente prefiero reservar esa denominación para un conjunto de incidentes con unidad interna que puede constituir por sí mismo un poema, pero que también puede formar parte de una composición mayor como la Odisea. Incluso no necesita tener una estructura continua, puede desarrollarse a lo largo de una obra paralelo a otros temas, aflorando aquí o allá. Èn la Odisea, por ejemplo, el tema del retorno del héroe no constituye la totalidad del poema, sino que se combina con las aventuras de Telémaco y la matanza de los pretendientes, pero además reaparece en el interior de aquéllas con Menelao como protagonista y de acuerdo con un patrón que reproduce, abreviado, el de los viajes de Ulises ${ }^{5}$.

Todos estos recursos encontramos en los poemas homéricos. En todos ellos se manifiesta una tipificación, una regularidad, un imponerse de esquemas generales que reflejan la influencia y el trabajo de una tradición poética, el éxito de ciertas fórmulas felices, útiles para el poeta, aprendidas por él y repetidas como técnicas de oficio. En ellas la tradición deja de ser un concepto ambiguo y amplio y se

1 H. F. Johansen, General Reflection in Tragic Rhesis, Copenhague, 1959.

C. R. Beye, "Homeric Battle Narrative and Catalogues, HSCP 68, 1964 , pp. $345-370$.

B. Fenik, Typical Battle Scones in the Iliad, Wiesbaden, 1968, p. 66 y 8. I21, 206, 213.

- A. B. Lord, Composition by Theme in Homer and Southslavic Eposs, TAPhA 82, 1951, pp. 71-80.

8 B. B. Powell, eNarrative Pattern in the Homeric Tale of Menelaus, TAPhA I01, 1970, pp. 419-430; M. F. Hansen, The Conference Sequence, Berkeley, 1972. 
resuelve en una serie de nociones concretas: oficio aprendido, lengua literaria, historias tradicionales, fórmulas, motivos, patrones, combinaciones de patrones, situaciones e incidentes, temas; todo esto puede tener o no tener sentido trasladado a la tragedia griega; en todo caso ese traslado no podrá ser una mecánica comparación para decir si existen o no existen paralelos; habrá que juzgar las respuestas en el propio contexto de la tragedia, en sus circunstancias históricas y teniendo en cuenta lo que sabemos sobre la transmisión de la cultura en la Atenas del siglo $\mathrm{v}$.

3. En primer lugar hay ciertas semejanzas obvias entre épica homérica y tragedia a las que ya hemos hecho referencia. Los poetas trágicos utilizan un material predeterminado tanto en lo que se refiere a la lengua como en lo que se refiere a la temática. Sus temas proceden de la tradición legendaria, elaborada por los poetas del ciclo épico y los líricos corales, que tenfa para ellos la ventaja, según nos recuerda Aristóteles, de ser auténtica historia y por tanto verosímil a priori. Por otro lado podríamos decir que se trataba de historias eminentemente adecuadas a las cualidades de un arte como la tragedia, si no incurriésemos con ello en un cierto círculo vicioso ya que esas cualidades proceden en parte del tipo de temas tradicionalmente empleados ${ }^{1}$.

En todo caso es este un aspecto, diriamos, débil de la tradicionalidad de la tragedia, ya que no exige ningún tipo de transmisión organizada ni ningún aprendizaje especial; bastaría la simple lectura, o mejor audición, de uno o dos poemas basados en una leyenda determinada, o incluso un simple relato no elaborado literariamente, para que el poeta trágico pudiese componer una tragedia de igual tema ${ }^{2}$. Hay sin embargo, un aspecto de la tradición más importante y que se nos aparece unido inseparablemente a la cuestión de los contenidos tradicionales. $\mathrm{Y}$ es precisamente en las escasas tragedias que se apartan aparentemente de la tradición como conjunto temático donde mejor podemos comprobar esta afirmación. No nos servirán de nada, por supuesto, ni Las Fenicias o la Toma de Mileto de Frínico, ni el Anthos

1 Aristóteles, Poet. I45rb, p. 12 y ss.; J. de Romilly, La tragédie grecque, Paris, 1970, p. 157 .

- Hablar de tradición, como decía al principio, no es suficiente; hay que distinguir grados de tradicionalidad atendiendo a la vez a diversos criterios que incluyen, entre otros, aprendizaje del poeta, tradicionalidad de la ocasión del poema y cauces tradicionales de su publicación. Aquí me limitaré, a falta de estudios previos más concretos, a hablar de tradicionalidad débil, en el sentido ya indicado, y tradicionalidad fuerte, que es la que intento mostrar en la tragedia. 
LA TRAGEDIA GRIEGA CONSIDERADA COMO UN OFICIO TRADICIONAL

de Agatón, de las que prácticamente lo ignoramos todo excepto la peculiaridad de que su argumento estuviese tomado de la historia contemporánea o fuese puramente imaginario ${ }^{1}$, pero los Persas de Esquilo si puede sernos muy reveladora a través de ciertas peculiaridades de su contenido y de su estructura.

En efecto, si consideramos las leyendas tradicionales de los griegos como un material previo, una especie de cantera a la que acudia el poeta trágico para recoger materiales, tendremos que incluir en esa consideración una serie de actitudes, de prejuicios o de intereses dominantes que podrían haber perdido por completo su vigencia en el siglo $\mathrm{v}$, pero que se manifiestan en el conjunto de esas leyendas y que podían ser asimilados por el poeta sin necesidad de un análisis consciente. Es el caso, por ejemplo, del importante papel que en las leyendas juegan las relaciones familiares y especialmente la figura del padre como determinante psicológico de la actitud del héroe trágico ${ }^{2}$. Cuando Esquilo toma de la realidad contemporánea los datos para sus Persas los adapta naturalmente a las convenciones externas de la tragedia, conscientemente asumidas por el poeta; de ahí la presentación de la campaña a través de escenas de mensajero y el papel importante del coro. Los adapta, también conscientemente, a una determinada interpretación religiosa y moral que por lo que sabemos debió ser bastante común entre sus contemporáneos. Pero además toma de la historia persa anterior la figura de Dario, la magnifica y la convierte en una pieza central de su obra que se adapta así al esquema familiar de muchas tragedias legendarias. No es probable que Esquilo, al obrar así, se dijese conscientemente: "vamos a introducir y resaltar la figura del padre de Jerjes para plegarnos al modelo de otras tragedias", pero no es dudoso que esas tragedias estaban condicionando su enfoque de Persas. La tradición se manifestaba inconscientemente.

Pero aún hay más. Hemos hablado de temas que pueden coincidir o no con el argumento de una obra, y que en todo caso consisten en una sucesión de situaciones, incidentes y combinaciones de patrones y motivos que les hacen perfectamente reconocibles y que pueden manifestarse en más de una leyenda. En este sentido el tema implica en gran medida la trama de una obra. Los Persas han utilizado, para narrar la historia contemporánea, un tema tradicional pero que no es pro-

1 B. Snell, Tragicorum Graecorum Fragmenta I, Gotinga, 1971, p. 74 y ss. y $\mathrm{r} 6 \mathrm{I}-2$.

- Datos recogidos, por ej., en R. S. Caldwell, "The Pattern of Aeschylean Tragedy", TAPkA ror, 1970, pp. 77-94. 
bable que fuese conscientemente reconocido en la época. Se trata del tema que pudiéramos llamar "la espera del regreso", para distinguirlo del "regreso" en sentido estricto, al que ya nos hemos referido a propósito de la Odisea y con el que puede formar una unidad más amplia.

Los Persas, en efecto, desarrollan un relato que en sus líneas más generales había sido ya elaborado por la tradición literaria anterior: un gran ejército ha partido en campaña con su rey al frente a un lejano país enemigo, ha pasado el tiempo, faltan noticias, llega el mensajero esperado, por fin regresa también el rey. Cualquier leyenda que se ocupe de una expedición militar puede presentar los hechos de acuerdo con ese esquema; a él se atiene en líneas generales la Odisea, a él se atiene el Agamennon y con complicaciones especiales las Traquinias de Sófocles e incluso la Helena de Euripides y en menor medida su Ifigenia en Tariride. De nuevo tenemos derecho a pensar que si Esquilo ha organizado los datos históricos de acuerdo con ese esquema, cuyo mérito literario ha sido subrayado tantas veces, ha sido no porque su intuición de poeta lo crease de la nada, sino porque inconscientemente ha sabido extraerlo de la tradición anterior ${ }^{1}$.

4. Hay, sin embargo, un problema que no podemos dejar de lado. Los Persas son la tragedia más antigua que se nos ha conservado y nuestros conocimientos de las obras anteriores perdidas es tan pequeño que no podemos asegurar que las coincidencias observables entre aquélla y la tragedia posterior reflejen características comunes al género desde sus primeros tiempos. No está excluida la posibilidad de que esas caracteristicas hayan nacido en fecha avanzada o que reflejen una tradición no especfficamente trágica. Cuestión esta que nos lleva de nuevo al problema del oficio frente a la mera tradición. Precisando más, el problema es el siguiente. Si los recursos tradicionales que empleó Esquilo en la composición de los Persas manifiestan un grado de tradicionalidad débil, es decir explicable por simple imitación, más o menos consciente pero no sistemática, de obras poéticas anteriores, trágicas o no, y que no implica la asimilación de unos patrones que condicionan el proceso creador del poeta y le proporcionan unos cauces previos, no es necesario pensar en un oficio de dramaturgo, en una técnica adquirida por un aprendizaje deliberado. Esquilo ha podido actuar como el novelista moderno, que toma de aquí y de allá temas o recursos, expresiones o rasgos de estilo, sin que eso implique, como decíamos antes, un fuerte grado de tradicionalidad en su obra. En ese caso estaría muy lejos de ser un profesional en el sentido en que lo es el poeta

1 J. de Hoz, On Aeschylean Composition I, Salamanca, 1978, § 2.3.3.1. 
LA TRAGEDIA GRIEGA CONSIDERADA COMO UN OFICIO TRADICIONAL 181

homérico, o el pintor o el escultor del Renacimiento, que por muy original que pueda haber llegado a ser, había recorrido un largo aprendizaje en el taller de un maestro de más edad hasta adquirir la técnica necesaria para el desarrollo de su profesión ${ }^{1}$.

Es posible, sin embargo, que el análisis interno de la tragedia o la información externa que sobre ella poseemos nos dejen ver un auténtico proceso de formación técnica, al menos en algún aspecto de los muchos que abarca la compleja actividad del autor ateniense de tragedias. Podremos entonces atribuir un auténtico carácter profesional y tradicional, a la vez, a Esquilo y a sus sucesores e incluir en ese cuadro los aspectos débiles de la tradición, en sí no probatorios. Podremos también rechazar como modelos inmediatos de la composición trágica a los otros géneros sin que esto implique naturalmente negar su posible influencia en muchos casos aislados. Por supuesto el problema del origen de la tradición trágica se confundirá con el problema del origen de la tragedia y queda por completo fuera del campo de nuestro interés actual y de nuestras posibilidades de explicación también.

5. Planteada la cuestión en estos términos es de nuevo la epopeya oral el género que en principio puede ofrecer indicios sobre la forma más correcta de plantear.nuestras pesquisas. Hemos visto que los poemas homéricos nos mostraban una serie de mecanismos o recursos a través de los cuales se hacía sentir la tradición, y que implicaban un aprendizaje que separaba a algunos individuos del resto de la comunidad no simplemente como dotados de unas cualidades poéticas especiales sino, sobre todo, como conocedores de un oficio cuyas técnicas debían ser aprendidas. Los poemas homéricos no nos dicen prácticamente nada sobre este aprendizaje pero, gracias a los estudios comparativos sobre literaturas orales, podemos hacernos cierta idea del proceso. El futuro poeta, a través de la asociación con un profesional y la repetida audición de sus poemas, llega a memorizar lo que normalmente él cree ser la versión única de cada uno de ellos, aunque de hecho, dadas las condiciones de la improvisación oral, haya habido siempre diferencias de detalle y el propio memorizador incurra en cambios. Sobre la base de estas versiones aprendidas el poeta llega a estar en condiciones de extraer, intuitiva e inconscientemente, los diversos recursos de su arte, desde la lengua artificial y las fórmulas

1 A. Hauser, Historia social de la literatura y el arte, Madrid, 1964 y ediciones posteriores, capitulo V.3. 
hasta los temas abstractos ${ }^{1}$. Debemos preguntarnos si la sociedad ateniense del siglo $\mathrm{v}$ ofrecía alguna situación similar.

Los vasos áticos nos muestran frecuentemente desde el comienzo mismo del siglo $\mathrm{v}$ escenas escolares en las que se refleja el sistema típico de primera enseñanza tal como se practicaba en Atenas probablemente desde comienzos del siglo vi ${ }^{2}$. Es ese sistema al que debió someterse Esquilo y no nos cabe duda de que Sófocles y Euripides pasaron por él. De los testimonios que tenemos el más interesante para nuestro objetivo actual es el de Platón en el Protagoras: "Cuando (los niños) han aprendido las letras y empiezan a comprender lo escrito... (los maestros) ponen junto a ellos en sus bancos, para que las lean, y les obligan a aprenderlas de memoria, las obras de buenos poetas en las que se contienen muchas exhortaciones morales y relatos, encomios y alabanzas de los grandes hombres antiguos, para que el niño emulándoles les imite y se esfuerce en llegar a ser semejante a ellos» (325e).

Junto a estas palabras de Platón debemos colocar los numerosos testimonios que nos demuestran la importancia de las obras de Homero en la enseñanza; sabido es que no sólo era normal el conocimiento de largos pasajes de la Iliada y la Odisea, sino que algunas personas eran capaces de recitar ambos poemas completos ${ }^{3}$.

Es evidente después de lo dicho que la situación ateniense, en lo que se refiere a la tradición literaria en general, tiene ciertas semejanzas con lo que sabemos del aprendizaje de las técnicas orales de composición. Un muchacho ateniense medianamente dotado para la poesía se encontraba a una edad relativamente temprana en posesión no sólo de un número alto de leyendas tradicionales, cuya elaboración literaria se podía plantear conscientemente, sino de multitud de pasajes aprendidos de memoria de los que podia extraer por simple intuición multitud de recursos poéticos prefabricados. No es extraño en esas condiciones el continuo uso de elementos del dialecto épico por poetas atenienses pero tampoco lo es, dado que la lírica coral proporcionaba sin duda buena parte del material escolar, el que los trágicos atenienses no tuviesen ninguna dificultad en revestir de un cierto colorido dorio sus coros. Por lo menos un vaso con escena escolar nos permite leer

1 A. B. Lord, The Singer of Tales, Cambridge, Mass., 1960, p. 21 y ss.

2 K. S. Freeman, Schools of Hellas, Londres, 1922, p. 52; H. I. Marrou, Histoire de l'education dans l'Antiquite, Paris, 1965, pp. 79-80; T. B. L. Webster, Potter and Patron in Classical Athens, Londres, 1972, indice s. $u$. School; H. R. Immerwahr, Studies B. L. Ullman I, Roma, 1964, pp. 18-20.

s Jenofonte, Banquete III 5. 
LA TRAGEDIA GRIEGA CONSIDERADA COMO UN OFICIO TRADICIONAL 183

en el rollo que el alumno tiene en sus manos el comienzo de una composición coral $^{1}$.

Pero no sólo la lengua artificial de la literatura se podría transmitir a través de la escuela. Lo mismo podemos decir de temas abstractos, como el que hemos comentado a propósito de Persas. Más aún, al hablar de los patrones utilizados por los poemas homéricos me he referido a una forma especifica de reflexión general; es evidente que una enseñanza en que se procuraba que el alumno memorizase, con

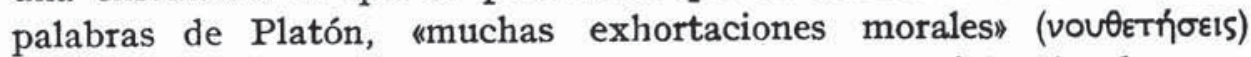
ponía a disposición de los jóvenes atenienses material sobrado para extraer el esquema abstracto de cualquier tipo tradicional de reflexión o de parénesis. En líneas generales podemos decir que todos los recursos que utiliza el poeta oral podían ser transmitidos por una enseñanza como la ateniense, incluida la fórmula ${ }^{2}$. El que ésta no aparezca en la literatura ática del siglo $\mathrm{v}$ sino en muy escasa medida, no se debe a las condiciones de aprendizaje y transmisión de la tradición, sino a la forma de componer que planteaba muy distintas exigencias al ateniense armado de papiro y cálamo y al aedo pre-homérico analfabeto.

Se nos plantea entonces un problema de importancia decisiva para comprender el carácter tradicional de la tragedia. ¿Bastaba con ese aprendizaje literario general para que el poeta trágico estuviese capacitado para ejercer su oficio? O dicho en otros términos, la tradición trágica, desde el punto de vista literario - no estoy hablando por supuesto de las convenciones institucionales del género ni de los aspectos musicales o histriónicos-, ¿era simplemente la tradición literaria sin más?

6. Antes de abordar este problema quiero, sin embargo, insistir en lo ya dicho sobre la importancia del aprendizaje memoristico utilizando el testimonio de otro género literario anterior en su desarrollo a la tragedia pero que, a diferencia de éste, llega a explicitar plenamente sus recursos y a organizar conscientemente un sistema de enseñanza a partir de la segunda mitad del siglo v. Me refiero, naturalmente, a la retórica.

Ciertas a nalogías de la retórica con la composición homérica oral ya han sido señaladas por algunos autores; como dice George Kennedyı

1 Immerwahr, op. cit., pp. I9 y 47.

2 El problema por supuesto va más allá de la tragedia y afecta a todos los géneros poéticos; por ej., habrla que plantearse desde este punto de vista la transmisión de motivos y combinaciones de motivos estudiados por F. Cairns en Generic Composition in Greek and Roman Poetry, Edimburgo, 1972. 
"the orators usually memorized their commonplaces, but, except for that feature, the construction of the speech resembled the composition of oral poetry out of themes and formulae ${ }^{1}$ ". Ahora bien, el interés de los oradores para nosotros estriba precisamente en la diferencia indicada por el profesor Kennedy y que no es simplemente esa memorización a la que alude sino el hecho de que el orador memorizaba con plena conciencia y con plena conciencia utilizaba luego los materiales almacenados en su memoria. Es ese el cambio esencial que la retórica trae consigo, el que un género apenas literario no sólo alcanza una dignidad nueva sino que se hace consciente de sus propias características, y de su tradición por lo tanto, y hace explícita esa tradición al organizar un sistema de enseîanza y transmisión de técnicas y recursos. Pero, naturalmente, lo que no podemos suponer es que esta auténtica revolución cultural, llena de consecuencias, positivas y más aún negativas, para el futuro, se hiciese a partir de la nada. En realidad la retórica no hizo sino tomar conciencia de una serie de recursos que eran comunes en su clase, aunque no en sus variedades particulares a los distintos géneros literarios cultivados en Grecia por entonces ${ }^{2}$. De ahí que la retórica inicial, si hemos de creer a Aristóteles, tuviese un carácter eminentemente práctico y memorístico, y no implicase ninguna novedad importante con respecto a la escuela tradicional. Asi parece deducirse de ur pasaje de las "Refutaciones sofísticas» (I83 b 36 ss.): "El tipo de enseñanza de los que obtenían dinero de la erística era similar a los procedimientos de Gorgias. En un caso se asignaba a los disć́pulos para que los aprendieran de memoria discursos retóricos, en el otro preguntas y respuestas, pensando ambos que en general recogían así los argumentos de uno y otro campo. Por ello la enseñanza era rápida pero carecía de método, pues creían que podían enseñar proporcionando no un arte sino sus productos, como si alguien afirmase que iba a proporcionarnos conocimientos para evitar daños a los pies y luego no enseñase el arte de la zapatería ni cómo es posible procurarse tal cosa sino que nos diese muchas clases de todas las variedades de calzados. Ese hombre habría acudido a resolver una necesidad práctica,

\footnotetext{
1 G. Kennedy, The Art of Persuasion in Greece, Londres, 1963, p. 53.

- La deuda inicial que la retórica griega contrajo con la poesía se acepta de ordinario - véase, por ej., F. Cairns, op. cit., p. 36- pero quizá no se adviertan todas sus implicaciones. La transmisión de los modelos retóricos, cuyo mecanismo conocemos, produce resultados similares a los de la transmisión de modelos poéticos en los períodos arcaico y clásico, cuyo mecanismo no conocemos. Nuestros conocimientos sobre la enseñanza retórica pueden y deben iluminar una investigación sobre el aprendizaje de las técnicas poéticas.
} 
pero no nos había proporcionado un arte». Como vemos no hay ninguna diferencia entre el aprendizaje retórico y la memorización escolar de fragmentos poéticos excepto que el primero tiene por objeto proporcionar la capacidad de componer nuevos discursos y el segundo se contenta con mejorar la cultura y sobre todo la moral del alumro. Ahora bien, sea cuales fueren los objetivos, si los medios eran idénticos también habrían de serlo los resultados. Hay, sin embargo, algunas diferencias que, aunque Aristóteles no las señale, sería vicioso ocultar. Nos consta que ya Antifón preparó con fines didácticos colecciones de introducciones y conclusiones, lo cual implica no sólo una idea clara de la estructura general del discurso, sino también de los recursos propios a cada una de sus partes ${ }^{1}$. Es éste un aspecto que nos interesa destacar aquí; el planteamiento sistemático y consciente de la composición de un género literario implica dar igual importancia a todas sus partes, incluidas las más desprovistas de contenido, por ejemplo transiciones, o de referencia más concreta a las circunstancias externas del género, el contexto legal por ejemplo, de mínimo interés humano fuera de las circunstancias especificas para las que el género fue creado. Hay aquí una diferencia notable entre la enseñanza tradicional ateniense y la enseñanza retórica; es evidente que un muchacho ateniense no aprendería series seguidas de despedidas hímnicas del tipo:

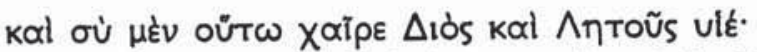

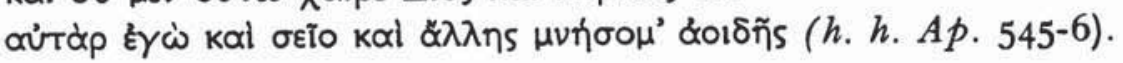

Es posible que palabras similares acudiesen instintivamente a sus labios si se le pidiese que compusiera la conclusión de un himno, pero ello seria debido a su conocimiento de himnos completos. El estudiante de retórica, por el contrario, tendría que aprender sistemáticamente lugares comunes tan poco interesantes como el que acabamos de mencionar, con objeto de componer adecuadamente un discurso.

Es decir que la atención prestada a la estructura del género en la enseñanza retórica iba desde el principio mucho más allá de los límites en que puede moverse la simple imitación superficial. No cabe duda de que cualquier ateniense que hubiera escuchado unos cuantos discursos públicos y la representación de unas cuantas tragedias podría advertir, cualquiera que fuese su educación, que ambos géneros tienen ciertas partes características, algunas de ellas especialmente llamati-

1 L. Radermacher, Artium scriptores, Viena, 1951, B X 13-5. 
vas, así la parte narrativa, el prólogo y el epílogo en el discurso, o los kommoi trenódicos, las rheseis de mensajero o la parodos en la tragedia. Pero estas observaciones superficiales no podian ser suficientes para los maestros de retórica que necesitabar enseñar la composición no sólo de aquellos momentos más característicos o notables, sino, como acabamos de ver, de cada uno de los elementos del discurso, incluidos los más insignificantes y subordinados a la construcción general.

Si comparamos con la tradición retórica lo que hemos podido observar en la tradición a que pertenece la poesía homérica vemos varias coincidencias: en ambos casos existe un oficio que exige un aprendizaje técnico, en ambos el medio principal de ese aprendizaje lo constituye la memorización de obras anteriores o sus partes; por último a los motivos homéricos corresponden los lugares comunes retóricos y a las situaciones, incidencias y temas corresponden !as distintas partes del discurso con su estructura peculiar y sus características propias. $\mathrm{Si}$ prescindimos de la lengua, que en el discurso por su carácter práctico debía ser naturalmente la de todos los días, no una creación artificial, sólo nos faltan en la retórica dos de las características señaladas en Homero, las fórmulas y los patrones formales. Las fórmulas ya vimos que en el grado en que aparecen en la poesía homérica son, más que una manifestación de simple tradicionalismo, el resultado de una forma específica de tradición cultural, la que se basa únicamente en recursos orales y está constreñida por un patrón métrico; no es éste, desde luego, el caso de la retórica griega que se ocupa de la prosa y que desde el primer momento hizo uso abundante de hypomnemata o notas escritas. En cuanto a los patrones formales no tenemos noticias de que nada similar fuera codificado y enseñado por la retórica primitiva pero la situación cambia cuando llegamos a Aristóteles y a los topos formales o elementos de los entimemas que se estudian en el libro segundo de su Retórica. No nos interesa ahora plantearnos hasta qué punto han sido sus investigaciones lógicas y la anterior tradición dialéctica las que han conducido a Aristóteles a tomar conciencia de los tópicos formales como recursos literarios; lo cierto es que el Estagirita ha examinado directamente las obras literarias, tanto oratorias como poéticas, y aún en el supuesto de que su definición y clasificación de los tópicos formales fuese aprioristica y puramente lógica, ha sabido documentar éstos en testimonios concretos ${ }^{1}$.

1 Rhet. 1397 a 7-1400 b 34. Aristóteles cita pasajes de Alcidamante, Euripides, Teodectes, Ificrates, Autocles, Safo, Aristipo, Isócrates, Lisias, Antifón el trágico, Androcles Piteo, Leodamas (?), Jenófanes y Carcino, aparte varios frag- 
LA TRAGEDIA GRIEGA CONSIDERADA COMO UN OFICIO TRADICIONAL 187

El primero de los tópicos citados por Aristóteles es el de los contrarios sobre el cual se expresa así: "Un tópico de los entimemas demostrativos es el de los contrarios, pues hay que observar si el contrario de un predicado es cierto y en caso de que no sea así negar el argumento, o, si si lo es, afirmarlo;.por ejemplo que ser moderado es bueno porque es perjudicial el ser inmoderado; o como en el Discurso Meseniaco: si la guerra es la causa de los males presentes es preciso repararlos por medio de la paz» (Rhet. I397a 7 ss.).

Aristóteles completa sus ejemplos con dos pasajes de tragedia, uno de autor desconocido, el segundo del perdido Thyestes de Eurípides. Si consideramos estos tres ejemplos desde el punto de vista de nuestros anteriores consideraciones tendremos que admitir que en ellos se manifiesta un patrón bien definido, útil en la composición literaria en toda clase de contextos reflexivos o parenéticos. Y lo mismo cabe decir de la mayor parte de los restantes tópicos citados por Aristóteles que, aunque él no ejemplifica como en el caso del primero, han sido observados por los filólogos modernos repetidamente en los discursos de los oradores áticos conservados ${ }^{1}$. Todos ellos son igualmente patrones en el sentido en que hemos empleado esa palabra al hablar de la poesía homérica.

Con Aristóteles, por lo tanto, la retórica antigua toma conciencia del último de los elementos constituyentes de una tradición literaria que hemos definido más arriba. Ahora bién, esto no quiere decir que Aristóteles haya inventado los patrones por él citados bajo el nombre de tópicos y cuya utilidad queda manifiesta en el uso que de ellos hizo 1a retórica posterior, especialmente Cicerón en sus Topica; Aristóteles se ha limitado a reconocer algo que ya existía en las obras de los oradores -y también de los poetas-, a darle nombre y a justificarlo desde un punto de vista lógico. Lo importante para nuestro objetivo actual es que esos patrones se han transmitido en la tradición desde mucho antes de Aristóteles, es decir desde antes de que se tomase conciencia de ellos y pudiesen ser objeto de una enseñanza explícita. Este hecho se explica por el aprendizaje memorístico que caracterizó a la retórica desde sus orígenes; el aprendiz de orador no escuchaba nunca una definición de un patrón formal determinado, el de los contrarios por ejemplo, pero

mentos anónimos y sin contar los entimemas aparentes ( 1400 b 35 y ss.) y las varias citas del topos basado en el nombre (1400 b 18-34) que es idéntico al recurso poético común conocido como figura etimológica.

1 Georgina P. Palmer, The tomón of Aristotle's Rhetoric as exemplified in the orators, Chicago, 1934; citada por Kennedy (p. 184, n. I), p. Ior, n. ror. 
aprendía de memoria una serie de discursos y partes de discursos en los que ese patrón estaba contenido y llegado el momento era capaz de abstraer instintivamente, por intuición, del arsenal de recursos almacenados en su mente, la pieza concreta que necesitaba. E1 proceso es paralelo al que permite a cualquier ser humano, hablante de una lengua cuya gramática no ha estudiado, abstraer a partir de las oraciones enteras que han constituido el material de su aprendizaje, formas $y$ funciones particulares que nunca le han sido enseñadas explicitamente.

La retórica, pues, como enseñanza de un género literario específico, el del discurso en prosa, se nos aparece como una paulatina toma de conciencia de recursos propios de cualquier literatura tradicional, comunes algunos de ellos a otros géneros griegos contemporáneos, incluso poéticos, otros especificos de la oratoria. Vemos también cómo, incluso antes de tomar conciencia de esos recursos, su enseñanza era ya un hecho a través del procedimiento de memorizar discursos enteros o partes características de ellos. La retórica en esto no ha significado ninguna ruptura violenta con el pasado, se ha limitado a plantear sistemáticamente lo que ya se venía haciendo desde siempre para conseguir una formación poética y musical ${ }^{1}$, lo que sin duda habían hecho ya los aedos homéricos y sus predecesores. La novedad de la retórica estriba en que desde el primer momento la práctica memorística se combina con ciertas reflexiones teóricas sobre los elementos del discurso que van descubriendo y definiendo explícitamente los recursos que el orador manejaba en forma instintiva. Estas definiciones explicitas ayudarían sin duda a la intuición del aprendiz pero no pretendían sustituir, al menos no lo pretendieron en la práctica, la memorización tradicional. Como mucho pudieron refinarla al introducir, junto al aprendizaje de discursos enteros, el aprendizaje de partes características, colecciones de prólogos o eṕlogos, por ejemplo, o de lugares comunes organizados por temas, como la colección de Eleoi o "modos de provocar compasión" que se atribuye a Trasimaco de Calcedón ${ }^{2}$.

7. ¿Y la tragedia, qué posición ocupa en esta perspectiva de la transmisión tradicional de los géne1os literarios? Como vimos ya, el problema que se nos plantea consiste en determinar si existía o no un aprendizaje específico que proporcionase los recursos tradicionales propios de la tragedia, o si el aprendizaje literario normal, quizá màs

1 A. M. Dale, Collected Papers, Cambridge, I969, p. $4 \mathrm{I}=C Q_{44}, \mathrm{r} 959, \mathrm{p} . \mathrm{I}_{38 .}$

F. Solmsen, $C P$ 33, 1938, p. 392; E. B. Stevens, $A J P 65,1944$, pp. 3, ro y 23; Kennedy (p. 183 n. I), p. 69, y cf. Radermacher (p. I85, n. I) B IX 6. 
LA TRAGEDIA GRIEGA CONSIDERADA COMO UN OFICIO TRADICIONAL 189

prolongado e intensivo, podía bastar a un joven ateniense para comenzar sus tanteos trágicos confiando en perfeccionarse con la práctica. Como ya vimos en el caso de las reflexiones generales la escuela podía proporcionar materiales sobrados como para que el estudiante llegase a abstraer el patrón y por lo tanto a ser capaz de reproducirlo; lo mismo podria decirse de muchos de los patrones recogidos por Aristóteles entre sus tópicos formales, ya que al servir especialmente a la parénesis o la reflexión debieron figurar entre los pasajes morales favoritos de 1a escuela. El problema estriba en determinar si al margen de rasgos muy llamativos y externos, fácilmente advertibles e imitables, la entrada anapéstica del coro por ejemplo, o de rasgos concretos y menos evidentes pero posiblemente bien representados en los pasajes que sirvieron a la enseñanza común, la tradición trágica incorpora rasgos exclusivamente suyos cuya pervivencia a lo largo de la historia de la tragedia implica cierto sistema en la transmisión de técnicas, una enseñanza organizada de algún modo en suma.

7.I. La respuesta a nuestras dudas sólo podremos encontrarla, por supuesto, en el texto mismo de las tragedias, pero antes de referir a él nuestro juicio convendrá que señalemos brevemente ciertos indicios externos, favorables o contrarios a la idea de una instrucción especffica exclusiva de la tragedia.

A favor podemos recordar que el autor trágico fue, durante los primeros tiempos de la tragedia al menos, su propio director de escena; a é le le correspondía la producción de la obra con todas sus implicaciones, desde los problemas económicos que debía resolver con arconte y corego hasta la escenificación final, música y decorado incluidas, pasando por la instrucción de coro y actores y la supervisión de los ensayos ${ }^{1}$. Por supuesto todo esto implicaba un cierto oficio adquirido y por lo tanto una voluntad y una dedicación conscientes que pudieron ser dirigidas también a los problemas estrictamente literarios del género.

En segundo lugar es bien sabido que en muchos casos la profesión de poeta trágico, como la de ceramista, era hereditaria y se transmitía dentro de una familia ${ }^{2}$. Así ocurre en el caso de los tres grandes trági$\cos$ y en otros menos conocidos, como el de la familia de Carcino que se prolonga al menos cuatro generaciones. El caso de la familia de Es-

1 Sir Arthur Pikard-Cambridge, The Dramatic Festivals of Athens, Oxford, 1968 (edición revisada por J. Gould y D. M. Lewis), pp. 84-6 y 91.

2 Ceramistas: T. B. L. Webster, Potter and Patron in Classical Athors, London, 1972, p. 9 y 88. Poetas trágicos: A. E. Haigh, The tragic Drama of the Greeks, Oxford, 1896, p. 429 y ss. 
quilo es especialmente llamativo por el número de poetas en ella comprendidos: a la segunda generación pertenecen Euforión y Bión, y un sobrino del fundador, Filocles. Un hijo de éste, Mórsimo, continúa la tradición familiar hasta la quinta generación a través de su hijo y nieto, Astidamente el viejo y Astidamente el joven.

En tercer lugar podemos citar la rapidez de composición que caracteriza a los autores dramáticos atenienses, evidente en el número de obras de que tenemos noticia y, con menos claridad, en las condiciones mismas del concurso trágico, ya que es probable que los poetas no presentasen al arconte obras completas, sino proyectos que no terminarían sino después de tener la seguridad de ser admitidos al concurso ${ }^{1}$.

Por último otro indicio a favor de un aprendizaje específico del oficio trágico lo tenemos en el hecho, tantas veces comentado desde Platón, de que ningún poeta trágico fuese a la vez poeta cómico, a diferencia de lo que ocurría con otros géneros poéticos. En principio la explicación más simple de este fenómeno no tendría el carácter un tanto metafísico que recibe en Platón, sino que sería más bien técnica; sobre la base común de los recursos poéticos, tragedia y comedia imponían técnicas particulares y el aprendizaje de unas implicaba ya una especialización que excluía normalmente a la otra. El caso de Ion, único autor a la vez de tragedias y comedias del que tenemos noticias, parece ser la excepción que confirma la regla.

Pero junto a estos indicios, favorables a la idea de una instrucción trágica especifica, existen otros de sentido contrario que no debemos silenciar. En primer lugar el número, alto incluso en el siglo $\mathrm{v}$, de poetas no atenienses. De los cinco poetas trágicos del canon helenístico dos eran extranjeros instalados en Atenas, Ion de Quios y Aqueo de Eretria, y entre otros poetas más o menos destacados habría que añadir a Aristarco de Tegea y Neofrón de Sición antes de que la tragedia, en el siglo IV, deje de ser patrimonio ateniense para convertirse en una institución panhelénica. Por desgracia los escasos restos conservados de estos poetas impiden comprobar la existencia de rasgos distintivos en su obra frente a la de los atenienses ${ }^{2}$.

Otro dato destacable es la existencia, desde fines del siglo $\mathrm{v}$, de auténticos amateurs, gente de variados intereses que entre otras ocupaciones literarias o intelectuales en sentido amplio han podido, ocasionalmente y sin regularidad ninguna, consagrar sus esfuerzos a la

1 Pickard-Cambridge, op. cit., p. 84.

- B. Snell, Tragicorum Grascorum Fragmenta I, Gotinga, I971, Ig (Ión), 20 (Aqueo), I $_{4}$ (Aristarco), I5 (Neofrón). 
tragedia. Critias, el político destacado entre los treinta tiranos, podría encabezar una lista en la que figuran filósofos como Diógenes o Crates, y Dionisio el tirano de Siracusa ${ }^{1}$. De nuevo aquí nos faltan textos que permitan comprobar si las tragedias de estos autores se apartaban en algo del estilo tradicional de los profesionales; en todo caso conviene insistir en la existencia de un conjunto de recursos tradicionales que iba más allá de los límites de cualquier género poético determinado, y que incluso en algunos aspectos al menos cabalgaba sobre la frontera de prosa y verso, dada la influencia indudable que desde el primer momento ejerció la poesía sobre la retórica y la corriente inversa que se produce desde fines del siglo v. No cabe duda que los mismos recursos que sirvieron a Critias para componer sus elegias y sus discursos pudieron ayudarle también en la redacción de sus tragedias. En cuanto al siglo Iv pocos poetas cita Aristóteles con tanta frecuencia como Teodectes de Faselis, bien conocido como retórico. Es sintomático que Aristóteles pueda utilizar a menudo pasajes tomados de sus tragedias precisamente para ilustrar procedimientos de argumentación ${ }^{2}$.

7.2. Todos estos indicios exteriores nos han llevado de nuevo por lo tanto a la disyuntiva previamente señalada. Existe una tradición cultural griega transmitida desde la escuela por vía memorística que en cierto modo basta para hacernos considerar cualquier obra literaria del siglo v o IV como producto de una instrucción y un aprendizaje en un sentido muy distinto, mucho más condicionante, de lo que dejan ver las tradiciones literarias en el mundo contemporáneo. Sobre esa base común de recursos adquiridos cualquier poeta griego, ateniense o no, profesional de la tragedia o no, ha podido con ayuda de un conocimiento externo de las características del género y siempre que contase con la ayuda técnica de un director de producción, componer tragedias aceptables. El problema estriba en averiguar si la obra de los auténticos trágicos, y en especial la de Esquilo, Sófocles y Eurfpides, muestra, además de esos recursos comunes a toda la literatura poética de su época, otros especificos de la tragedia y a la vez lo suficientemente sutiles como para implicar un aprendizaje especial. La respuesta naturalmente está en nuestros textos, en ellos veremos si existen o no esos rasgos especificos; en especial sería decisivo mostrar la existencia de recursos secundarios, no cargados de ningún contenido descollante,

1 Snell, op. cit. 43 (Critias), 88 (Diógenes), 90 (Crates), 76 (Dionisio).

- Snell, op. cit., 72; fragmentos I, 2, 3, 3a, 5, 5a y 5b citados por Aristóteles. La mayor parte de los restantes proceden de Estobeo. 
y a la vez necesarios para la composición de la tragedia como obra dramática, es decir, para aquello que ésta tiene de nuevo frente a todos los géneros anteriores.

Hemos indicado ya de pasada que los diversos tipos de recursos que existen en la epopeya homérica, con excepción de las fórmulas, existen también en la tragedia. En realidad podríamos ir más lejos y afirmar que casi todo en la tragedia es recurso de ese tipo, aunque el escaso número de piezas conservadas y las diferencias cronológicas que las separan no nos permiten comprobar esta afirmación tan directamente como en el caso de los poemas homéricos, e insisto en las diferencias cronológicas porque desde luego no podemos cometer el error de confundir tradición y estancamiento, ni siquiera tradición y conservadurismo. Como ya he dicho el sentido en el que me interesa el concepto de tradición es en el de transmisión de técnicas, transmisión continua en la que los autores, una vez adquirida su competencia profesional, son capaces de introducir modificaciones que a su vez encuentran un cauce adecuado y natural para ser transmitidos a los generaciones siguientes; no podemos perder este hecho de vista si pretendemos juzgar adecuadamente nuestros textos ${ }^{1}$.

Pero volvamos en busca de materia concreta para nuestras reflexiones a una tragedia ya mencionada aquí y que tiene el interés para nosotros de ser la primera de las que conservamos, los Persas de Esquilo. Los elementos formales con que Esquilo compuso los Persas son relativamente escasos: relatos en trímetros yámbicos o en anapestos, plegarias cantadas, lamentaciones cantadas y dialogadas, pasajes de contenido sentencioso y poco más ${ }^{2}$. Todos esos elementos mencionados tenían ya una larga tradición en la literatura griega, todos ellos formaban parte del acervo más común en la tradición que constitúa la cultura literaria escolar. Por otro lado ya hemos visto cómo la historia que da tema a la tragedia, con no ser tradicional, se organizaba de acuerdo con temas tradicionales del tipo más general y comín a varios géneros literarios. Nos queda sin embargo por examinar ciertas formas visibles en esa tragedia que pueden proporcionarnos el tipo de argumento que necesitamos; a ellas volveremos en seguida.

1 Las posibilidades y la flexibilidad de la tradición en las literaturas orales - el antecedente de la poesia griega de los siglos vi y v- y en la composición retórica - su continuadora - se ponen de manifiesto respectivamente en $\mathbf{R}$. Finnegan, Oral Poetry, Cambridge, 1977, passim, y F. Cairns, Generic Composition in Greek and Roman Poetry, Edimburgo, 1972, especialmente capitulos 2 y 4 .

- J. de Hoz, On Aeschylean Composition I, Salamanca, 1978, passim. 
Otra tragedia què conserva un cierto prestigio de primitiva, aunque hoy día sepamós que no se la puede atribuir una fecha tan antigua como en tiempos se supuso, son las Suplicantes del propio Esquilo. En las Suplicantes encontramos igualmente una serie de recursos ya tradicionales antes de los comienzos de la tragedia, en parte los mismóos que hemos señalado en los Persas, e incluso la hístoria misma dramatizada formaba parte del patrimonio heredado y había sido elaborada antes de Esquilo y de Fŕńnico, autor de otra tragedia del mismo tema, en la epopeya cíclica. En un sentido distinto al de los Persas también aquí podremos encontrar indicios de una tradición especf́ficamente trágica ${ }^{1}$.

- Del poema épico Danais ${ }^{2}$ conservamos un fragmento citado por Clemente de Alejandría que dice así:

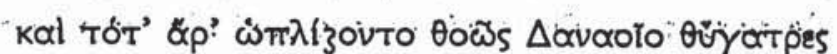

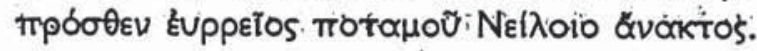

Poco es para hacerse una idea siquiera remota del contenido del poemä, pero al menos nos demuestra que en buena tradición épica el anónimo atitor deđicó una parte de sus 6.500 versós a la descripción de los enfrentamientos entre Egipcios y Danaides que condujeron a là derrota y' huída de éstas a Argos. Como sabemos Esquilo prescinde de toda esa parte en su presentación de la historia y comienza con la llegada de las Danaides" a Argos como suplicantes. Toda la acción de su tragedia se desarrolla en torno al altar en el que han buscado refugio las Danaides y se reduce esencialmente a tres movimientos: la entrada del rey de Argos cuya protección buscan conseguir las Danaides y finalmente obtienen; 1a entrada del heraldo egipcio que pretende arrancar violentamente a las suplicantes de su refugio sagrado; la nueva entrada del rey de Argos que se enfrenta al heraldo egipcio y protege a las Danaides. Esstos tres motivos básicos que podemos denominar suplica, agresión y defensa constituyen un conjunto de incidentes comparable con los temas épicos. En ellos vemos ya desarrollada la situación del suplicante tal como va a vivir a lo largo de toda la literatura del sigla $\mathrm{v}$, bien como contenido de una tragedia completa, bien como tema

1 Sobre las relaciones de Danais y Suplicantes sigue siendo básico Wilamowitz, Aischylos Interpretationen, Berlin, I9I4, p. I 2 y ss. Estudio reciente de Danais: G. L. Huxley, Greek Epic Poetry, Londres, I969, p. 34 y ss.

- G. Kinkel, Epicorum Graecorum Fragmenta, Lipsiae, 1877, p: 78. E1 fragmento citado es el número $x$. 
parcial pero importante ${ }^{1}$. Essquilo volverá a utilizarlo en las Eumenides, Sófocles lo hará en Edipo en Colono, pero sobre todo será Eurípides, el que utilizará al máximo el recurso en Heraclidas, Andromaca, Suplicantes, Heracles e incluso Ion y Helena. El motivo del suplicante no es por supuesto desconocido en la tradición anterior a la tragedia; podemos citar por lo menos dos formas caracteristicas en la Iliada, el guerrero derrotado que suplica por su propia vida al vencedor, bien ejemplificado en el episodio de Licaón en el canto $2 \mathrm{r}$, y el del anciano que suplica en el campo aqueo la devolución de un hijo, prisionero o muerto, motivo con el que se abre el poema pero importante sobre todo en la conclusión con el rescate de Héctor. Lo que es nuevo es la particular conformación del motivo y la incorporación de elementos que desconocemos en la tradición épica. En buena medida estas novedades responden a las condiciones peculiares de un género dramático que en vez de narrar puede mostrar una historia, y mostrarla no sólo con palabras, sino también con acciones y objetos; de ahi el papel del altar como foco central en torno al cual se organizan los motivos. Por otro lado, otros motivos típicos del drama y que en él se han desarrollado independientemente aunque podamos rastrear su origen en la literatura anterior, han contribuido a dar su forma a este complejo patrón; en este sentido es especialmente significativo el enfrentamiento de protector y agresor que recibe naturalmente la forma propia del llamado agon, es decir, la escena en que, por medio de discursos contrapuestos y del diálogo estilizado conocido como stichomythia, se muestra el duelo dialéctico entre dos personajes ${ }^{2}$.

En definitiva lo que importa es que a partir de las Suplicantes de Esquilo encontramos en la literatura griega un complejo de motivos que constituyen en conjunto algo nuevo y que va a pervivir a lo largo del fragmento de historia de la tragedia que nos es dado observar directamente. En esa pervivencia se marifiesta indudablemente algo que podemos llamar tradición, ¿pero qué clase de tradición? Ya señalé antes que existe lo que podríamos llamar tradición débil; me refiero a la persistencia de recursos literarios que se basa no en el aprendizaje de una técnica, sino en la imitación de obras anteriores que el poeta observa desde fuera, dirfamos, sin llegar a hacer suyos los recursos

1 J. Kopperschmidt, Die Hikesie als dramatische Form, Bamberg, 1967, y Hilkesie als dramatische Forms (pp. 32I-46 de W. Jens (ed.), Die Bauformen der Griechischen Tragodie, Munich, 197I). Cf. también J. Gould, «IKETEIAs, JHS 93, 1973, p. 103.

I. Duchemin, L' ATWN dans la tragédie grecgue, Paris, I945. 
imitados, sin incorporarlos a su propio arsenal de respuestas naturales e inmediatas ante un determinado problema de composición. Que este tipo de imitación se da también en la tragedia griega es indudable; nos lo demuestra en primer lugar su antitesis, es decir aquellos pasajes en que Euripides deliberadamente apunta las soluciones adoptadas por sus predecesores en una escena concreta y las rechaza, especialmente los versos célebres de Electra en los que la heroina rechaza la posibilidad de poder reconocer los cabellos o la huella de los pies de su hermano comparándolos con los suyos propios tal como ocurria en las Coeforos de Esquilo ${ }^{1}$. La critica expresada por Euripides en casos como este, la que él mismo ha sufrido a manos de Aristófanes con tanta frecuencia, ponen de manifiesto la posibilidad de que en la tragedia griega se haya sobrepuesto a la formación poética general recibida por los autores una cierta tradición débil, manifiesta en la imitación de esta o aquella escena que alcanzó éxito o que resultaba cómoda para resolver un problema de escenificación. Cualquier lector de Literatura moderna no dudaria en juzgar así las escenas de crimen y gritos que desde el Agamenón (1343 ss.) de Esquilo se repiten tantas veces -en Coefforos (869 ss.), Medea (127I ss.), Hécuba (r034 ss.), Heracles (749 ss., 887 ss.), Ciclope (663 ss.), Orestes (1269 ss.) y la Electra de Sofocles (r404 ss.) -; en todos estos casos el problema es el mismo, presentar ante los espectadores una escena de violencia difícilmente representable por razones técnicas en un escenario clásico, y también la solución es idéntica: se escenifica la entrada de la futura víctima en el interior de un secinto, la puerta se cierra y se oyen sus gritos en el interior ${ }^{3}$. Casos como éste no serian en sí más significativos que la repetición de monólogos ajustados a la técnica del ustream of consciousness» en la novela contemporánea; a lo sumo habria que interpretar repeticiones de este tipo en la literatura griega clásica como siempre se ha hecho, como testimonios del poco valor que entonces se daba a la originalidad literaria, o al menos a la originalidad en la invención de temas y situaciones.

Esta actitud, sin embargo, no resulta satisfactoria por diversas razones. Como ya he dicho prácticamente cada pasaje de una tragedia

1 Electra, p. 520 y ss. T. B. L. Webster, The Tragedies of Euripides, Londres, 1967, p. 12 y ss., se ocupa de la imitación y adaptación consciente de las tragedias anteriores por parte de Euripides.

- J. de Romilly, L'Evolution du Pathetique d'Eschyle a Euripide, Paris, 196r, p. 52 y ss.; R. Kannicht, Untersuchungen zu Form und Funktion des Amoibaion in der attischen Tragodie, tesis doctoral de la Universidad de Heidelberg, I957. p. 243 y 88. 
griega puede encontrar paralelos en otras tragedias, bien sea en el patrón formal al que se adapta, bien en los motivos que combina, bien en el papel que juega en la composición de una escena, y lo que no parece verosímil es que los autores trágicos fuesen tan sensibles a los méritos de sus antecesores que ante cualquier problema técnico recordasen un pasaje concreto que les había parecido especialmente afortunado.

Además no podemos: supervalorar el papel del libro trágico, a pesar de Wilamowitz. Un autor podría recordar esta o aquella escena vista en alguna representación anterior, en algunos casos podría incluso recordar escenas leídas, lo que no podría frecuentemente es acudir a un texto en el que refrescar sus recuerdos con vistas a la imitación, tal como ocurre en el mundo moderno ${ }^{1}$.

Pero sobre todo hay que tener en cuenta una cierta densidad característica de 1 os ecos que observamos entre unas tragedias y otras, una familiaridad que pervade expresión y contenido $y$ que resulta extremadamente sensible para cualquier lector de tragedias en cualquier grupo de versos. Resulta difícil definir objetivamente esta impresión que responde a una cualidad de la tragedia inseparable de nuestro interés y de nuestros juicios de valor; algo en cierto modo similar al tacto que define la calidad de una tela. En cierto modo podríamos definirlo acudiendo una vez más al modelo épico; es en efecto la misma cualidad que en la poesía homérica podemos atribuir a ese complejo de recursos propios de los diversos niveles de la obra y que van desde la lengua a las historias narradas pasando por fórmulas, patrones y temas. Pero por otra parte, en el caso de la tragedia, esa cualidad característica aparece plenamente integrada a lo que la tragedia tiene de más nuevo y especifico, y en primer lugar a sus recursos dramáticos, a todo lo que en ella está condicionado por las necesidades de presenta-

1 F. D. Harvey, REG 79, I966, pp. 587 y 6or-3; H. R. Immerwahr, Studies B. L. Ullmann I, Roma, 1964, después de insistir en el desarrollo del libro en Atenas durante el siglo v (pp. 36-7) concluye: "The popular image of the book was not the prose book, nor the great epic or the tragic text, but epic tale, the short hymn, the gnomic collection, and the collection of lyric poems... From there the sophists, orators, and philosophers (more $t h a n t h e t r a-$ gedians) took up the cause of the book and spread its popular use further (p. 48; los espaciados son mios). Cf. también E. G. Turner, Athenian Books in the Fifth and Fourth Centuries B. C., Londres, 1951, pp. 21-2. Naturalmente las objeciones contra una difusión considerable del libro trágico no implican que los discipulos, familiares o no, de un poeta trágico no tuviesen acceso a los manuscritos originales de sus tragedias. 
ción ante un público. Es este término el más probatorio para mi argumentación y en él buscaré mis últimos ejemplos.

Vuelvo, pues, a los Persas donde, según dije, habíamos dejado algunos elementos formales sin mencionar. Es significativo que estos elementos, los que no tienen precedentes muy cercanos en la literatura anterior, sean precisamente tipos de diálogo y en concreto dos, la stichomythia y lo que llamaré "diálogo transicional». La stichomythia no necesita detenernos mucho puesto que se trata de una de las formas dramáticas más estudiadas y comentadas; sólo quisiera hacer una observación sobre ella: es cierto que basta haber escuchado un único pasaje esticomítico para captar la naturaleza del procedimiento y estar en condiciones de imitarlo, pero eso se refiere sólo a lo más exterior y visible y no alcanza a todas las caracteristicas de ese tipo de diálogo que, más allá de la pura alternancia de interlocutores verso a verso, consiste en la complicada red de relaciones que ensambla cada respuesta al verso precedente y que pone en acción los más variados recursos, asíndeton, elipsis, repetición de vocablos, interrupciones bruscas o juegos de palabras ${ }^{1}$.

Igualmente interesante desde nuestro punto de vista, aunque menos estudiado, es el elemento formal que he llamado "diálogo de transición" y cuyo desarrollo se justifica exclusivamente por el carácter dramático de la tragedia. Es de sobra conocido que la tragedia griega es un género en buena medida narrativo, que continúa en parte las antiguas formas de presentación indirecta de una historia y sólo en parte va sustituyéndolas por la presentación directa, escenificada. En los Persas Esquilo utiliza al mensajero como narrador de la campaña persa desde Salamina hasta que el ejército vencido cruza el Helesponto; para presentarnos esa auténtica estampa histórica el mensajero pronuncia en sucesión cuatro discursos de $28,80,25$ y 37 versos respectivamente, en total I 70 trímetros yámbicos que habrian podido constituir una unidad de longitud similar a la del himno homérico a Apolo Delio. El problema estriba en que en ese caso la verosimilitud dramática de la tragedia, la pretensión de representar a seres humanos en conversación, hubiera sufrido un rudo golpe. Por eso el poeta reparte esa materia narrativa en cuatro secciones diferentes e intercala

1 A. Gross, Die Stichomythie in der Griechischen Tragödie und Komödie, Berlin, 1905, p. 82 y ss.; J. L. Hancock, Studies in Stichomythia, Chicago, 1917, p. 26 y ss.; S. Ireland, "Stichomythia in Aeschylus", Hermes 102, 1974, pp. 509524 . 
entre ellas diálogos que responden a un esquema bastante definido ${ }^{1}$. Desde el primer momento la reina persa se constituye en interlocutor del mensajero al que una y otra vez interroga:

$$
\begin{aligned}
& \text { Tís oủ Tह́丶 } \\
& \tau \tilde{\omega} \nu \alpha \rho \chi \varepsilon \lambda \alpha \omega \nu . . . ;(296-7)
\end{aligned}
$$

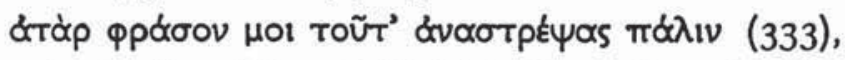

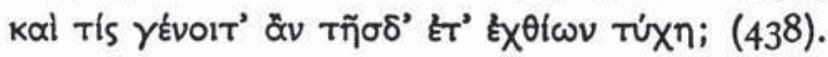

En cada caso la respuesta del mensajero es un pequeño avance o resumen del discurso que seguirá más adelante, y en cada caso esa respuesta, como ya el discurso precedente, provoca en la reina explosiones de sentimientos formalizadas y esquemáticas:

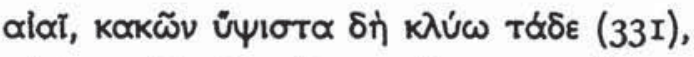

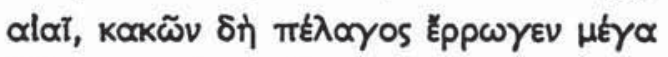

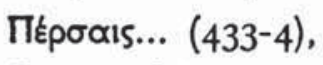

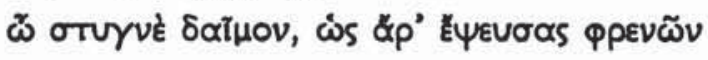

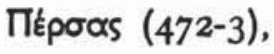

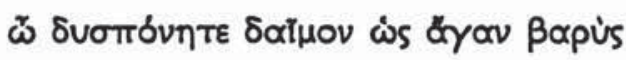

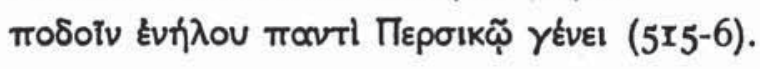

A menudo alguna gnome acompaña a esos comentarios y en cada caso todo se resuelve en una nueva pregunta que es la que da pie a uno de los largos discursos narrativos.

Esquema repetido por lo tanto; diálogo sometido a una formalización que no parece basarse en ninguna tradición pretrágica ya que el único género en que sería posible buscar esa tradición, los diálogos en estilo directo de la epopeya heroica, no parecen proporcionarnos ningún ejemplo, ni siquiera rudimentario, del tipo en cuestión.

En la tragedia posterior a Esquilo no encontramos esas series de discursos de mensajero separadas por diálogos; aparentemente se ha abandonado por lo tanto el modelo que acabamos de examinar. Sin embargo no es asi; cada escena de mensajero en Sófocles y Eurípides se atiene a un patrón seguido sistemáticamente. El mensajero, a menudo anunciado como en Persas, entra en escena y bruscamente, tam-

1 J. de Hoz (p. I9I, n. 2), capitulo I. 
LA TRAGEDIA GRIEGA CONSIDERADA COMO UN OFICIO TRADICIONAL

bién como en Persas, declara que trae graves noticias. No pasa sin embargo inmediatamente a su discurso; antes tiene lugar un diálogo en el que reconocemos con toda claridad el modelo ya descrito ${ }^{1}$; el interlocutor pregunta:

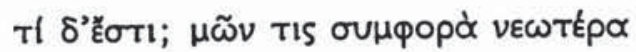

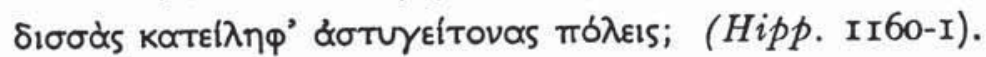

E1 mensajero resume:

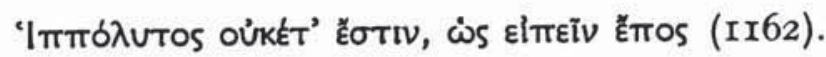

E1 interlocutor expresa su dolor con oraciones de sintaxis formularia:

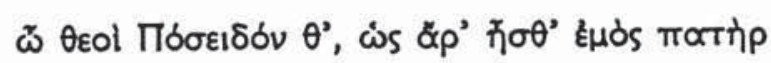

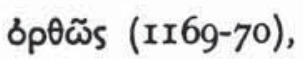

y renueva sus preguntas hasta conseguir que el mensajero inicie su relato pormenorizado:

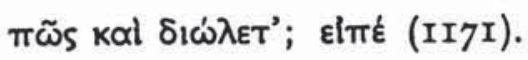

Este patrón que encontramos en cinco tragedias de Sófocles, doce de Eurípides, entre ellas las Bacantes e Ifigenia en Aúlide, y en el Reso, es decir, a lo largo de toda la historia del género, nos prueba, a mi modo de ver, que ha existido una tradición trágica con recursos especificos, ignorados por los restantes géneros poéticos clásicos, y a la vez lo suficientemente poco llamativos y visibles como para no justificarse por una simple imitación consciente. De casos como éste deduzco la existencia de un auténtico adiestramiento en la técnica de poeta trágico que, dadas las condiciones y los hábitos de la época, difícilmente pudo tomar una forma que no fuese memorística.

Permítaseme, pues, acabar con una imagen, inventada por supuesto pero que resume la hipótesis más sobria que a mi modo de ver justifican nuestros datos; la imagen de un joven ateniense, quizá Euforión,

1 J. Keller, Struktur und dramatische Funktion des Botenberichtes bei Aischylos und Sophokles, tesis doctoral de la Universidad de Tubinga, 1959, p. 7, con la bibliografia anterior en p. 3, n. 3 . 
el hijo de Esquilo, sentado en su banco en la actitud que nos muestran los vasos áticos de escenas escolares, sosteniendo en sus manos el rollo de papiro de una de las tragedias de su padre, y memorizando sus versos uno por uno, aprendiendo un oficio que exigia una larga y dura preparación y que, como el pancracio o la carrera en los que triunfaban los clientes de Píndaro, no conducía a ninguna profesión, sino a un concurso, y por él a esa gloria que los griegos adoraron casi enfermizamente.

J. DE $\mathrm{HOZ}$ 